\title{
AÇÕES INCLUSIVAS: EM UMA RELAÇÃO DIALÓGICA COM A COMUNIDADE LOCAL
}

\author{
MARLI DANIEL ${ }^{1}$ \\ ORCID: 0000-0001-5874-0341 \\ Juliana CARla Girotto ${ }^{2}$ \\ ORCID: 0000-0002-4916-3922
}

MÁrCia Zahner KLein ${ }^{3}$

ORCID: 0000-0002-1889-3412

Marlova Elizabete BalKe ${ }^{4}$

ORCID: 0000-0002-9786-8249

Resumo: Neste relato são apresentadas ações relacionadas à execução do projeto de extensão "Promoção de ações inclusivas para pessoas com deficiência no Campus Erechim do IFRS", que se desenvolveu embasado na interação com entidades sociais inseridas na comunidade local, promovendo a socialização de conhecimentos na área da inclusão. $O$ projeto envolveu professores, alunos, servidores e comunidade externa, sendo desenvolvido de forma interdisciplinar junto às áreas de conhecimento dos cursos de Moda e Vestuário e de Engenharia Mecânica que possibilitaram a elaboração de material pedagógico, realização de palestras, oficinas e minicursos visando a integração das ações desenvolvidas com as entidades. Observou-se que a inclusão escolar está relacionada ao processo de democratização da escola envolvida na comunidade a qual está inserida. Dessa forma, o NAPNE - Núcleo de

1 DANIEL, Marli. Doutoranda em Direito pela Universidade de Santa Cruz do Sul. E-mail: marli. daniel@erechim.ifrs.edu.br

2 GIROTTO, Juliana Carla. Mestre em Educação pela Universidade de Passo Fundo. E-mail: juliana. girotto@erechim.ifrs.edu.br

3 ZAHNER, Márcia Klein. Especialista em Educação pela Universidade Regional Integrada do Alto Uruguai e das Missões. e-mail: marcia.klein@erechim.ifrs.edu.br

4 BALKE, Marlova Elizabete. Doutora em Engenharia de Alimentos pela Universidade Integrada do Alto Uruguai e das Missões. E-mail: marlova.balke@erechim.ifrs.edu.br 
Atendimento às pessoas com Necessidades Específicas do Campus Erechim, desenvolveu ações significativas que envolvessem estes indivíduos difundindo informações, ideias, conceitos, práticas e conhecimentos para contribuir com a cultura de respeito à diversidade em nosso sistema educacional promovendo atitudes propícias à inclusão social.

Palavras-chave: Cidadania. Inclusão. Interdisciplinaridade. Indissociabilidade.

Abstract: This report presents actions related to the implementation of the extension project "Promotion of inclusive actions for people with disabilities in the IFRS Campus Erechim", which was developed based on the interaction with social entities inserted in the local community, promoting the socialization of knowledge in the area of inclusion. The project involved teachers, students, servers and external community, being developed in an interdisciplinary way in the areas of knowledge of the Fashion and Apparel and Mechanical Engineering courses that enabled the elaboration of pedagogical material, conducting lectures, workshops and mini courses aimed at the integration of the actions developed with the entities. It was observed that the school inclusion is related to the process of democratization of the school involved in the community to which it is inserted. In this way, NAPNE - Center of Assistance to People with Specific Needs of Campus Erechim, developed significant actions that involved these individuals disseminating information, ideas, concepts, practices and knowledge to contribute to the culture of respect for diversity in our educational system promoting attitudes to social inclusion.

Keywords: Citizenship. Inclusion. Interdisciplinarity. Indissociability.

Resumen: En este relato se presentan acciones relacionadas con la ejecución del proyecto de extensión "Promoción de acciones inclusivas para personas con discapacidad en el Campus Erechim del IFRS", que se desarrolló basado en la interacción con entidades sociales insertadas en la comunidad local, promoviendo la socialización de conocimientos en el área de la comunicación la inclusión. El proyecto involucró a profesores, alumnos, servidores y comunidad externa, siendo desarrollado de forma interdisciplinaria junto a las áreas de conocimiento de los cursos de Moda y Vestuario y de Ingeniería Mecánica que posibilitaron la elaboración de material pedagógico, realización de conferencias, talleres y minicursos visando la integración de las acciones desarrolladas con las entidades. Se observó que la inclusión escolar está relacionada al proceso de democratización de la escuela involucrada en la comunidad a la que está inserta. De esta forma, el NAPNE - Núcleo de Atención a las personas con Necesidades Específicas del Campus Erechim, desarrolló acciones significativas que involucrar a estos individuos difundiendo informaciones, ideas, conceptos, prácticas y conocimientos para contribuir con la cultura de respeto a la diversidad en nuestro sistema educativo promoviendo actitudes propicias a la inclusión social.

Palabras clave: Ciudadanía. Inclusión. Interdisciplinariedad. Inseparabilidad.

Recebido em: 10/12/2018

Aprovado em: 20/12/2018 


\section{INTRODUÇÃO}

A inclusão em espaços educativos tem sido pautada com maior ênfase nos últimos anos, fruto de um debate que defende um modelo, através do qual o conceito de educação especial se modifica, apresentando uma perspectiva que integra a pessoa com deficiência ao ensino regular.

Para o presente trabalho, inclusão pode ser compreendida como um conjunto de práticas que subjetivam os indivíduos a olharem para si e para o outro, fundadas em uma relação platônica das relações; ou, pode ser entendida como uma condição de vida em luta pelo direito de se auto representar, participar de espaços públicos, ser contabilizado e atingido pelas políticas de Estado. Pode ser entendida também como conjunto de práticas sociais, culturais, educacionais, de saúde, entre outras, voltadas para a população que se quer atingir, acompanhar ou regulamentar (LOPES, 2009).

Aparenta ser um tema bastante desenvolvido, muitas foram as políticas adotadas nos últimos anos para dar conta de um sem número de miseráveis, pessoas com deficiência, velhos em situação de abandono, crianças e jovens nas ruas, desempregados, enfim, um incontável número de pessoas que se encontram em situação de vulnerabilidade social, cultural, educacional, etc.

Apesar do tema inclusão, estar bastante difundido, muito ainda precisa ser feito, por isso, o trabalho também teve como objetivos problematizar as práticas inclusivas, a integração entre diferentes grupos sociais, contextualização das condutas docentes no contexto da educação inclusiva sob o olhar das carências da formação docente.

Por isso, o Instituto Federal de Educação, Ciência e Tecnologia do Rio Grande do Sul - IFRS, através da sua política de ações afirmativas, embasa as ações de inclusão com a premissa de respeito à diversidade e à defesa dos direitos humanos. Neste sentido os Núcleos de Atendimento às Pessoas com Necessidades Educacionais Específicas, coletivo presente em todos os Campi do IFRS, constituem-se como mediadores da educação inclusiva, organizando e estimulando projetos e programas educacionais para a convivência, consciência da diversidade e principalmente para a busca de quebra das barreiras arquitetônicas, educacionais, atitudinais e de comunicação.

O Projeto de Extensão Promoção de ações inclusivas para pessoas com deficiência no IFRS Campus Erechim baseou-se nos pressupostos de uma educação de qualidade para todos, observando, desde o princípio que a inclusão escolar está 
relacionada ao processo de democratização da escola, e dessa forma o NAPNE do Campus Erechim do IFRS inserido na comunidade local, desenvolve atividades significativas no âmbito da Inclusão de pessoas com necessidades específicas na Educação.

Percebeu-se a necessidade de desenvolver ações e atividades sobre educação inclusiva a fim de atender satisfatoriamente as necessidades que emergem de determinados grupos, especialmente aqui falando dos deficientes visuais, físicos, surdos e com autismo, propôs um projeto que promovesse a difusão de informações, ideias, conceitos, entre outras, de forma construtiva e dialógica, para contribuir com a cultura de respeito à diversidade em nosso sistema educacional.

Nesta perspectiva o projeto de extensão "Promoção de ações inclusivas para pessoas com deficiência no IFRS Campus Erechim” está embasado, observando que a inclusão escolar está relacionada ao processo de democratização da escola, contribuindo com a disseminação de uma cultura de respeito à diversidade em nosso sistema educacional.

\section{PRESSUPOSTOS TEÓRICOS}

Desde 1948 temos assegurado o direito à educação para todas as pessoas por meio da Declaração Universal dos Direitos Humanos, adotada e proclamada pela Assembleia Geral das Nações Unidas. Já em nossa Constituição de 1988, em seu artigo $1^{\circ}$, incisos II e III, se estabelece o direito à "cidadania" e a "dignidade da pessoa humana", representando que às instituições públicas devem promover ações de inserção social para a igualdade de oportunidades e a humanização das relações sociais (THOMA; HILLESHEIM, 2011, p.19).

Nesta perspectiva, destacamos também a Declaração de Salamanca, de 1994, que traz o conceito de Educação Inclusiva:

Escolas inclusivas devem reconhecer e responder às necessidades diversas de seus alunos, acomodando ambos os estilos e ritmos de aprendizagem e assegurando uma educação de qualidade à todos através de um currículo apropriado, arranjos organizacionais, estratégias de ensino, uso de recurso e parceria com as comunidades. [...] (p.5)

Cumpre ressaltar que a Declaração de Salamanca influenciou fortemente as políticas educacionais brasileiras, sendo que em 2001 o Plano Nacional de Educação (Lei no 10.172/2001) confirma que: “o grande avanço que a década da 
educação deveria produzir será a construção de uma escola inclusiva, que garanta o atendimento à diversidade humana”. (Item 8 - Educação Especial - 8.1 Diagnóstico), após este tão importante documento outros se somam, culminando com a Política Nacional de Educação Especial na Perspectiva da Educação Inclusiva, que logo no início de seu documento deixa claro:

O movimento mundial pela educação inclusiva é uma ação política, cultural, social e pedagógica, desencadeada em defesa do direito de todos os estudantes de estarem juntos, aprendendo e participando, sem nenhum tipo de discriminação. A educação inclusiva constitui um paradigma educacional fundamentado na concepção de direitos humanos, que conjuga igualdade e diferença como valores indissociáveis [...]

Da mesma forma, a Lei Brasileira de Inclusão da Pessoa com Deficiência (Estatuto da Pessoa com Deficiência), promulgada em 2015, destaca no artigo 27 que:

A educação constitui direito da pessoa com deficiência, assegurados sistema educacional inclusivo em todos os níveis e aprendizado ao longo de toda a vida, de forma a alcançar o máximo desenvolvimento possível de seus talentos e habilidades físicas, sensoriais, intelectuais e sociais, segundo suas características, interesses e necessidades de aprendizagem.

Falando em termos de educação, a inclusão tornou-se uma tarefa e um desafio para todos aqueles que devem velar pela educação, notadamente, deve-se apoiar que a formação em direitos humanos esteja sempre presente no decorrer de todo o processo educativo, seja de forma transversal ou através de disciplinas específicas inseridas do conteúdo curricular.

Atendendo a esses objetivos, o projeto teve um juízo positivo, pois apresentou um compêndio básico para conhecer, entender e justificar outras formas de promover a inclusão.

Para desenvolver o trabalho, foi necessário saber quantos são e como são os sujeitos incluídos ou excluídos, que dele fazem parte, quais as suas especificidades, as suas capacidades e as suas necessidades. Conhecê-los, portanto, se tornou imprescindível para definir e articular as estratégias de ação e de desenvolvimento das atividades propostas.

Neste viés a equipe envolvida no projeto embasou sua proposta, nas necessidades dos indivíduos atendidos por entidades locais, com o olhar para o ambiente escolar, no qual a inclusão de pessoas com deficiência vem sendo um acontecimento real e desafiador. Desta forma buscamos firmar parcerias com importantes associações da nossa comunidade, sendo elas: ADEVE 
(Associação dos Deficientes Visuais de Erechim), ADAU (Associação dos Deficientes Físicos do Alto Uruguai) e AQUARELA (Associação Pró Autista de Erechim), a fim de compartilhar saberes a partir das especificidades das pessoas com deficiência, suas particularidades e necessidades, promovendo a partilha de conhecimentos.

Comungamos das palavras de Malvezzi (2009) que afirma que:

Uma educação inclusiva implica colaboração e co-participação de toda a sociedade e deve se alicerçar na reconstrução da prática da democracia e da cidadania, reconhecendo e respeitando as diferenças individuais; buscando valores e práticas comuns; convivendo na diversidade, como sinônimos de integração e inclusão; valorizando a pessoa e garantindo seu acesso e permanência na escola. (MALVEZZI, 2009, p.3780)

Com base nas premissas iniciais o projeto foi desenvolvido a partir dos aspectos defendidos institucionalmente e a partir da política da extensão sem, contudo, deixar de lado seu vínculo direto com o ensino e com a pesquisa, uma vez que envolveu estudantes, docentes e servidores técnicos na estruturação, articulação e desenvolvimento das ações.

O entendimento presente durante o desenvolvimento do trabalho é de que o capital humano e a responsabilidade social superam o simples cumprimento do princípio da legalidade e assim igualdade formal corresponderá à igualdade material e, que por sua vez, igualdade significa viver em um ambiente equilibrado, harmonioso, onde educação, saúde, alimentação, moradia e trabalho com salário digno incluam as pessoas a um universo de possibilidades em igualdade de condições.

Como aborda Gorczevski, a educação: "Não obstante sua excepcional importância para a economia e o desenvolvimento de uma sociedade, a educação é, antes de tudo, um direito humano destinado a tornar o indivíduo um cidadão" (GORCZECSKI, 2016, p.219).

Para atingir os objetivos do projeto foram desenvolvidas atividades de cunho social, cultural e também de cunho formativo que visaram despertar a importância da inclusão das pessoas com necessidades específicas de forma ampla e irrestrita, pois o desenvolvimento humano compreende, não somente o crescimento e o desenvolvimento econômico, mas também o bem-estar das pessoas, a qualidade de vida que elas possam apresentar.

Com isso, o projeto procurou por meio de ações de extensão promover a aproximação do Campus Erechim do IFRS com instituições que atendem pessoas com 
deficiência no município de Erechim e região, promovendo a convivência, troca de saberes, experiências e possibilitando maior acolhimento de estudantes com deficiência no Campus Erechim.

Da mesma forma, o projeto se propôs a contribuir com o trabalho desenvolvido pelas entidades, fortalecendo as atividades educativas e motivando os associados envolvidos nesta organização, preparando as pessoas para uma inclusão social de fato, pois, tornou-se frequente e universal reclamar-se por direitos.

Assim, nos dizeres de Fernández-Largo:

Reclama-se em nome dos indivíduos, dos grupos, das classes sociais, dos povos e dos regimes políticos. Essa prática comum e generalizada argui o estado avançado da consciência moral dos seres humanos. A razão não pode ficar alheia a essas atitudes, antes, deve converter-se no baluarte onde se refugiem todas as reivindicações de justiça e de onde possam defender-se dos ataques da irracionalidade, da opressão e da desigualdade entres os homens (FERNÁNDEZ-LARGO, 2016, p.19). (...)

Além disso, ressalta-se que nos últimos anos, o ingresso do aluno com necessidades educacionais específicas nos espaços de ensino representam um avanço, porém ainda não são significativos a ponto de entendermos que não é necessário atitudes de chamamento inclusivo, ou seja, ainda existe um longo caminho a ser percorrido para que a inclusão se efetive plenamente.

Por isso, entendeu-se fundamental estabelecer parceria com as entidades de apoio: Associação dos deficientes visuais de Erechim- ADEVE, Associação dos Deficientes Físicos do Alto Uruguai - ADAU e Aquarela Pró Autista, instituições de extrema relevância e importância tanto no aspecto formal como material, pois, apresentam-se como referência social nos mais diversos aspectos aos atendidos, representa trilhar o caminho juntos e assim ser possível compreender melhor às necessidades dos grupos para proporcionar as ferramentas adequadas de inclusão.

\section{AÇõES DESENVOLVIDAS E O VÍNCULO GOM ENSINO, PESQUISA E EXTENSÃO}

Com base nas premissas iniciais o projeto foi desenvolvido a partir dos aspectos defendidos institucionalmente a partir da política da extensão sem, contudo, deixar de lado seu vínculo direto com o ensino e com pesquisa, uma vez que envolveu estudantes, docentes e servidores técnicos na estruturação, articulação e desenvolvimento de todo o projeto. 
O entendimento que esteve presente durante o desenvolvimento de todo o trabalho é de que o capital humano e a responsabilidade social superam o simples cumprimento do princípio da legalidade e assim igualdade formal corresponderá à igualdade material e, que por sua vez, igualdade significa viver em um ambiente equilibrado, harmonioso, onde educação, saúde, alimentação, moradia e trabalho com salário digno incluam as pessoas a um universo de possibilidades em igualdade de condições.

Pois, como bem aponta Gorczevski, a educação: "Não obstante sua excepcional importância para a economia e o desenvolvimento de uma sociedade, a educação é, antes de tudo, um direito humano destinado a tornar o indivíduo um cidadão" (GORCZECSKI, 2016, p.219).

Das pesquisas realizadas para se pensar o projeto, percebeu-se que a inclusão e a acessibilidade estão inter-relacionadas com o desenvolvimento sustentável, cultural, econômico, social e político, devendo estar relacionados com a proteção do meio ambiente, devendo ser buscado por toda a sociedade, garantindo aos vulneráveis uma melhoria na sua condição de vida, e um sentido real de justiça social, bem-estar e dignidade humana, pois os direitos fundamentais estão coligados e devem ser respeitados reciprocamente.

Por isso, para atingir os objetivos do projeto foram desenvolvidas atividades de cunho social, cultural e também de cunho formativo que visaram despertar a importância da inclusão das pessoas com necessidades específicas de forma ampla e irrestrita, pois o desenvolvimento humano compreende, não somente o crescimento e o desenvolvimento econômico, mas também o bem-estar das pessoas, a qualidade de vida que elas possam ter e o respeito ao meio ambiente.

As atividades desenvolvidas foram organizadas em diversos encontros, iniciando-se pelo estudo do tema e do referencial teórico. Foram elaborados os cronogramas e os planos de trabalho dos bolsistas envolvidos no projeto, atividades estas que foram organizadas na forma de reunião, planejamento, estudo bibliográfico e desenvolvimento prático através de encontros, palestras e oficinas.

Destacamos que o projeto envolveu bolsistas, aos quais coube zelar pela sua organização, realizar pesquisas bibliográficas, auxiliar no planejamento e execução das ações e apresentação dos resultados através de da participação de eventos internos e externos à instituição. Além disso, é importante ressaltar que para a formação dos estudantes tanto acadêmica quanto para o mundo do trabalho, também foram respeitados, além do plano de trabalho, os regulamentos do IFRS para que pudessem conciliar as ações do projeto com o 
andamento do curso regular ao qual estavam vinculados. Para os estudantes envolvidos percebeu-se um complemento na sua formação humana pelo envolvimento com as entidades parceiras que atendem pessoas com deficiência, bem como pelo convívio com o público atendido.

Com o intuito de contribuir para o embasamento de conceitos, enriquecimento de seus conhecimentos e também como base norteadora nas atividades que foram executadas, os bolsistas foram orientados na efetivação de leituras de artigos, livros, dissertações e legislação com temas relacionados com a temática do projeto, especialmente voltados para a inclusão.

"Não temos formação para ensinar estudantes com necessidades específicas". Essa frase confrontou a equipe do projeto em diversos momentos com esse argumento, nos mais diferentes contextos, desde educadores do ensino fundamental até o superior. Por isso, a partir dos levantamentos iniciais do projeto, resultou na preocupação que apontou para a necessidade de se produzir momentos de formação, imprescindível para o desenvolvimento de práticas nas diferentes categorias da diversidade.

Assim, destacamos o desenvolvimento de ações de formação através do projeto, uma vez que, foram realizadas palestras, oficinas e relatos de experiência, envolvendo a participação das entidades e do público por elas atendido, estudantes e servidores do Campus Erechim do IFRS, e comunidade externa em geral. As palestras realizadas abordaram temas sobre dificuldades e desafios vivenciados pela pessoa com deficiência, relatos de experiência abordando o complexo tema da inclusão e suas dificuldades, realização de oficina sobre o Braille e atividades de formação para profissionais da educação.

No desenvolvimento de material pedagógico com o auxílio dos estudantes dos cursos Técnico em Mecânica e Engenharia Mecânica, foram aplicados os conhecimentos abordados no curso para a confecção do material "Lego do Alfabeto Braille", sendo que, os estudantes utilizaram os softwares de desenho assistido por computador (Inventor) e de programação em linguagem CNC (EdgeCAM) em que foi possível programar e analisar todo o processo de usinagem, garantindo resultados eficazes na produção do alfabeto. As peças foram desenvolvidas de forma individual em nylon, material leve e de longa durabilidade, usinadas no laboratório de CNC do Campus Erechim do IFRS. Como resultado foi construído um alfabeto Braille completo, com as letras, numerais e sinais gráficos utilizados na leitura e escrita do Braille que foi doado para a ADEVE utilizar em suas atividades pedagógicas e formativas. 
Já os estudantes do Curso de Tecnologia em Design de Moda, em uma oficina de ilustração tátil, realizaram a customização de livros infantis com a utilização de aviamentos e resíduos têxteis gerados pelo curso. Os livros infantis receberam a customização para apresentar um relevo que permite a identificação do elemento em destaque na história e sua forma representada (animal, flor, cabelo, vestido, etc.). Após a finalização, estes receberam o texto escrito em Braille, permitindo assim que a leitura das histórias fosse adaptada para a alfabetização de pessoas cegas.

Também foi desenvolvido pelos estudantes do Curso Técnico Concomitante em Produção de Moda, no componente curricular de Composição de Imagem de Moda, a confecção de objetos texturizados e customizados com materiais que permitem a experimentação tátil, permitindo a associação das cores à objetos, fenômenos da natureza, animais, frutas, entre outros, presentes no dia a dia dos indivíduos mas que invisível aos deficientes visuais.

Ainda, foram desenvolvidas atividades de apoio às entidades de cunho informativo e de fortalecimento: divulgação do programa Nota Fiscal Gaúcha; incentivo e conscientização para arrecadação ao programa Tampinha Legal, desenvolvimento de material de divulgação para Brechós mantidos pelas entidades; divulgação de campanhas específicas de cada entidade (pedágios, chás beneficentes, palestras, jantares...). As ações de divulgação demonstraram-se necessárias, pois, as entidades apresentam sérios problemas financeiros, passando por um período de desamparo de políticas públicas.

\section{CONSIDERAÇÕES FINAIS}

O projeto buscou estimular os estudantes a desenvolverem diversas habilidades, relacionando o conhecimento teórico e prático, vinculados com as necessidades da comunidade externa à instituição.

Percebeu-se que os estudantes conseguiram desenvolver as atividades propostas no projeto, contribuindo para o andamento e finalização do mesmo, demonstrando amadurecimento e conscientização para o tema inclusão, o que foi possível visualizar pelas tarefas e atividades realizadas.

A construção dos materiais pedagógicos para as instituições demonstrou a possibilidade de auxiliar na inclusão de pessoas com deficiência, gerando uma valorosa contribuição social, respeitando as particularidades e diferenças. 
Percebeu-se que o público externo foi muito receptivo, apoiando e auxiliando no andamento das atividades propostas, experiência que contribui com a formação dos profissionais e fortalece os laços de respeito e valorização do ser humano.

A importância da educação, bem como a necessidade de se implementar uma educação direcionada ao respeito e ao exercício dos direitos humanos, parece ser matéria pacífica e unânime, no entanto ela não é tarefa tão simples assim e o desafio justamente reside em como concretizá-la.

Diante deste contexto o projeto realizou situações de aprendizagem com atividades práticas a partir dos saberes prévios dos estudantes, utilizando diferentes espaços e materiais disponíveis nas associações parceiras, assim como no Campus Erechim, permitindo desta forma a socialização e sistematização dos conhecimentos construídos e estratégias para incluir pessoas com necessidades específicas de modo que os pressupostos teóricos sejam articulados com a prática, diante da realidade local, regional e mundial, pois a educação precisa estar articulada com as dinâmicas dos movimentos sociais que emergem constantemente das demandas postas pela sociedade no seu constante processo de evolução.

Com isso, o projeto relacionou a educação inclusiva com temas fundamentais de dignidade humana e cidadania com o intuito de sensibilizar e conscientizar para a importância de uma sociedade envolvida e preocupada com questões que afetam tantos especialmente em momentos de tanta turbulência e insegurança econômica e social.

É possível afirmar que o projeto abriu espaço para a discussão, debate e reflexão sobre inclusão, diversidade, respeito, empatia e acessibilidade demonstrando a necessidade de reforçar ações e projetos relacionados ao tema que proporcionem conhecimentos que contribuam com a cultura de respeito à diversidade.

Ao se discutir a inclusão sem a pretensão de apontar soluções ou caminhos, nem realizar juízos de valor, percebeu-se que a partir das diferentes problematizações é possível reconfigurar nosso olhar sobre o outro e o diferente. A inclusão não é algo que se possa dizer que é boa ou ruim, mas sim, necessária para colocar em funcionamento um tipo de sociedade como a que vivemos.

Por isso, a partir de diferentes problematizações e abordagens é possível desnaturalizar alguns conceitos que são compreendidos como se sempre estiveram presentes, mostrando como foram montados e desmontados, de maneira a nos fazer pensar que existem outras formas de ver e nos relacionar com a diferença.

Ao desnaturalizar tal noção se torna possível experimentar outras posições, outros modos de olhar esses "outros" para a inclusão. Que ao menos se 
possa olhar, pensar e falar outras situações utilizando-nos de lentes que nos ajudam a colocar algo sob suspeita, que provoca novas formas de ver, pensar e falar sobre o sujeito da inclusão, bem como sobre a escola e seus espaços de educação inclusiva, buscando compor outras cenas educativas e novos modos de relação com a diferença.

Nesse sentido e, para finalizar, mais do que um direito conquistado por anos de luta pelos mais diferentes movimentos sociais e políticos, mais do que uma questão moral e ética, a inclusão deve ser entendida como uma forma de gerir as diferenças, que opera sobre a conduta de todos e de cada um de nós, controlando os riscos produzidos pela exclusão social e garantindo uma vida digna para todos.

\section{REFERÊNCIAS BIBLIOGRÁFICAS}

ARRUDA, Marcos. Tornar real o possível: a formação do ser humano integral, economia solidária, desenvolvimento e o futuro do trabalho. Editora Vozes. São Paulo, 2006. Brasil. Lei No 9.094/96, de 20 de dezembro de 1996. Disponível em: http://www.planalto.gov.br/ccivil_03/leis/19394.htm. Acesso em: 24 abr 2018.

BRASIL. Constituição Federal de 1988. Disponível em: http://www.planalto.gov.br/ccivil_03/constituicao/constituicaocompilado.htm. Acesso em: 15 fev. 2018.

BRASIL, Lei No 13.146 de 06 de Julho de 2015. Lei Brasileira de Inclusão da Pessoa com Deficiência - Estatuto da Pessoa com Deficiência. Disponível em: http://www.planalto. gov.br/ccivil_03/_Ato2015-2018/2015/Lei/L13146.htm. Acesso em: 10 fev. 2018.

BAUMAN, Zygmunt. La riqueza de unos pocos nos beneficia a todos? Trad. de Alicia Capel Tatjer. Paidós. 1ª Edición. Espanã, 2014.

BRESSER PEREIRA, Luiz Carlos. Estratégia Nacional e Desenvolvimento. Revista de Economia Política, São Paulo, v. 26, n. 2, abr/jun, 2006.

Documento Orientador do Programa Incluir: Acessibilidade na Educação Superior. Ministério da Educação. Disponível em: http://portal.mec.gov.br/programa-incluir. Acesso em: 10 dez. 2018.

GORCZEVSKI, Clovis. Direitos Humanos, educação e Cidadania: conhecer, educar, praticar. 2. ed., Santa Cruz do Sul: Edunisc, 2006.

Brasil. Declaração Universal dos Direitos Humanos. Disponível em: https://www.unicef.org/brazil/pt/resources_10133.htm. Acesso em: 15 dez. 2018.

LOPES, Maura Corcini. Inclusão como prática política de governabilidade. In: LOPES, Maura Corcini; HATTGE, Morgana Domênica (Org.). Inclusão escolar: conjunto de práticas que governam. Belo Horizonte: Autêntica, 2009. p. 107-130. 
MALVEZZI, Maria Demele Gasparino. Educação Inclusiva sob olhar da experiência. IX Congresso Nacional de Educação - EDUCERE; III Encontro Sul Brasileiro de Psicopedagogia. PUCPR, 2009, p.3779-3792.

THOMA, Adriana da Silva; HILLESHEIM, Betina. Políticas de Inclusão: gerenciando riscos e governando as diferenças. Edunisc. Santa Cruz do Sul, 2011. 